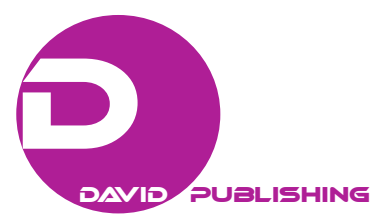

\title{
Who Populates the Visual Landscape of the ELT Coursebooks?: A Photo Analytical Exploration
}

\author{
Devrim GÜNAY \\ Istanbul University, Istanbul, Turkey
}

\begin{abstract}
The aim of this study is to portray and explore the variety of social actors depicted visually along the pages of the intermediate level ELT coursebooks that are published locally (by British and American publishers) and marketed globally (mostly to the EFL contexts). For this, a thorough photo-ethnographic exploration of the visuals supported by the inventory of "social actor interaction network" is employed. In the field of Coursebook Analysis, visuals have attracted limited attention despite marking asocio-semiotically rich discursive field. In fact, the semiotic labor division between the "word" and the "image" in representing and reconstructing (simulating) the world, points to a gain on the part of the image as the brain is evolutionarily more experienced in processing visual information than processing verbal information. Therefore, images can appeal more directly to the sensory experience domains of the viewers via visual contact, evoking deeper consciousness. Acting as the prominent mediators of signification practice, visuals catalogue the representations and simulations of social-life viewed from a particular subject position associated with a particular set of norms, beliefs, and values. Hence, they position the viewers across dynamic loci of subjectivities in terms of social distance, relations, and interaction. As both reflections and reproductions of reality, images in the coursebooks have the potent to influence learners' perspectives of the world presenting them with readymade cognitive schemes. In order to reveal a comprehensive picture of the visually depicted social actors and the identity options made available through them, in this study the author focused on the peopled photos of the 6 popularly traded ELT coursebooks. The author investigated them regarding the relations of social distance, involvement, power and interaction formed between the depicted social actors and their viewers as well as the emergent practices of exclusion, role allocation, genericization, specification, assimilation, individualization, and categorization. The results show that the representational repertoires of the coursebooks contain disproportionately distributed visual depictions of social actors in terms of cultural orientation and gender. The "culturally different" are repeatedly pictured in assimilative ways as an aggregate of enumerable people, while the social actors of the reference group are usually pictured individually and with their own intended meaning.
\end{abstract}

Keywords: visual communication, critical discourse analysis, Coursebook Analysis, photo ethnography, semiotics, language teaching

\section{Introduction}

It is an ordinary day in the hot and dry climate of Africa (see Figure 1). The trees on the sides of the road have blossomed with purple flowers. Two women are carrying food and barrels of water to their homes on barefoot along the dusty road. An almost invisible man on his motorbike is approaching them from the remote 
end of the road. Some hardly identifiable people have gathered on the side of the road for the open market event. Their faces cannot be distinguished from the oblique angle and the "public distance" the photo was taken. None of the people are aware that they are being photographed; they neither demand nor establish any relation with the viewer. Blurred in the distance, the social actors in the photo convey the meaning intended and constructed by the photographer (the implied author of the photo). They are there to realize the representation of social life in a small African village as it is viewed from the photographer's perspective. Their feelings, mimes, and gestures are not graphically included in the representation; rather, they are employed as the decorative figures in the background of the homoglossic view of "Africa" intended by the photographer. They are portrayed and treated as a community of strangers not to be acknowledged individually; as aggregate of people practicing a single shared culture; that of a homogenous Africa; one envisaged by the photographer to depict the African society.

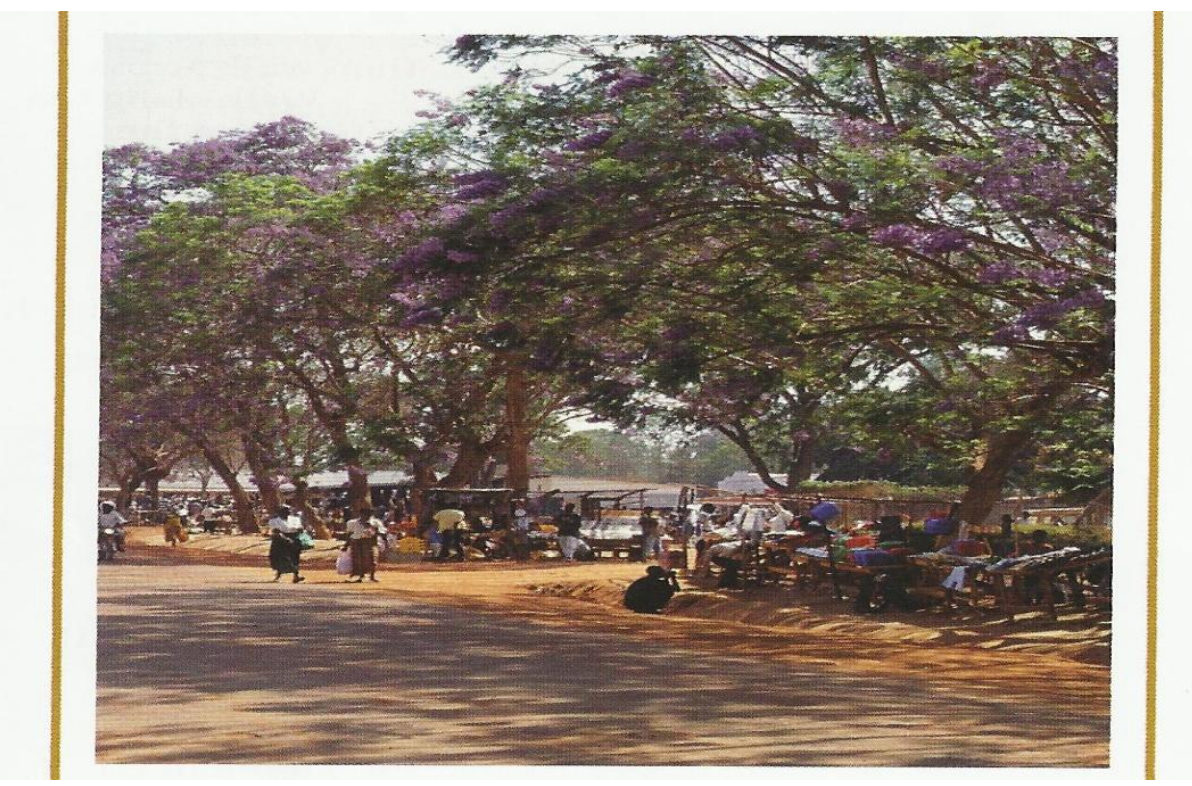

Figure 1. A distanced homoglossic representation of African social actors from English Result.

Intended to represent cultural life in Africa, the above depicted photo in Figure 1 goes under the title of "African Stories" in an intermediate level English Language Teaching Coursebook. When an assumed viewer looks at the image, she/he is invited to see the African world in a particular way, through a perspective associated with a particular set of norms and values. The assumed viewer of the image (similar to the implied reader of a book) is, then, positioned along an array of possible subject positions pre-determined by the photographer; either as an observer to the people, distant from the world of experience and meaning they have constructed or as a participant of the social context in varying degrees of attachment to it. Thus, within the bounds of the "semiotic landscape" where the image belongs, a "visual grammar" which makes possible a variety of interpretations and positionings to the viewers is in effect (Kress \& Van Leeuwen, 1996, p. 16). In this sense, the image, which is preliminarily conceived as a product of the visual sensory organs, goes beyond the "visual and retinal" borders of meaning making and is located in the broader and manifold domain of discourse where non-visual tools of interpretation are equally in use (Baetens, 2013, p. 185). This can be attributed to the fact that seeing is a conceptual, metaphorical, and linguistic process as well as a literal one 
(McDougall et al., 2006, p. 2). Therefore, any photo, including the depiction above is not simply put there to "represent curricular content" but also to construct a subjective point of view; to convey a communicative intention and thereby to say something about the portrayed people and their world.

Given this double role of photographic image both as the representation of subjectivity and as the abstraction of observed reality (J. Collier \& M. Collier, 1986, p. 10), the visual content of the coursebooks that embody a variety of visual representations of people, locations and cultures indispensably comes under question. Representation exists in the multi modal signs of the text situated in the coursebooks; in the multi-faceted fields of discourse, in the verbal, visual, sensual layers of semiosis. Particularly when foreign language teaching materials are concerned, it becomes crucial to find out who is portrayed how with regard to which cultural, gender, ethnic, national identities and what selective information is conveyed to the learners about them throughout the "representational repertoires" of the coursebooks. This significance emerges from the fact that coursebooks are among the major components of classroom practice and while "diverse classroom practices offer learners a range of positions from which to speak, listen, read or write", monolithic practices equally risk presenting a "color-blind" picture of the people and their world to the same degree (Norton \& Toohey, 2011, p. 429). At this point, exploring the variety of identity options made available to the learners visually along the pages of the coursebooks gains prominence, as they potent shaping and altering learners' perceptions of people and their culture. Given this vitality, the current research sets out to seek answers to the following central questions:

(1) What variety of social actors with regard to their cultural, ethnic, and gender orientations is depicted visually in the intermediate level ELT coursebooks to what extent?

(2) What relations are formed between the assumed viewers and the visually depicted social actors in terms of social distance, social relation, and social interaction?

In order to come up with suggestive responses to these questions and to portray a comprehensive picture of the representational repertoires inherent in the coursebooks, the author attempt to take into account and combine two analytical perspectives that could potentially give out fruitful results. First of these is a consideration of coursebook analysis frames from the field of ELT. The second is a photo-ethnographic point of view that informs us about the semiotic order and the many relations formed around the photographic image between the represented participants and the interactive participants (the viewers) of the photo.

\section{ELT Coursebooks as Semantic Repertoires of Identities}

Representation, particularly of culture and identities, has been a debatable issue in the field of language teaching, as language itself is both constitutive and constructive of representations that unavoidably reflect subjective stances towards given reality. Coursebook analysis, as a separate field of research in ELT, has usually dealt with written texts and linguistic representations as the primary field of investigation in addition to the more traditional areas of consideration such as content inclusivity, range of topics covered, variety of accents in the multi-media components, intercultural content, cultural encounters, etc. Hence, coursebooks have only recently been recognized as repertoires of visual representations (Gray, 2010) with the inculcation of perspectives inspired by critical discourse analysis and semiotic research into coursebook analysis.

In one such study Bedford (2005) raises the issue of racial identities and their representation in Business English coursebooks with specific reference to the professional roles assigned to people and their race. Upon an investigation of the coursebooks through the appraisal tool of the systemic functional grammar, a predominance 
of American and British accents were evidenced to take place among the findings. What's more, a link between the native speaker perception and race was also indicated by this study.

Shardakova and Pavlenko's (2004) research on identity options in Russian text books from another significant perspective to the related field of research. Establishing a link between identity construction and foreign language text books through a critical theory of language, they explore the identities constructed in the socially situated categories of social class, professional occupation, age, gender, sexuality, marital status, ethnicity, and religion. Their findings indicate that the identities of the imagined learner community envisioned by the coursebook were represented as "heterosexual, white, middle class male who goes to Russia to experience adventures" while the social actors were also mostly limited to "white middle class men/women who constitute romantic interests" (Shardakova \& Pavlenko, 2004, p. 43). The findings and results reached by Pavlenko and Shardakova may be taken as an indicator of inadequacy of most course books to represent a multiplicity of voices through their texts.

Gray's (2010) analysis of the English coursebooks with a focus on the neo-capitalist representations of the world of work points to a commercialized English Language Teaching and takes text books "not only as mediating tools of subject knowledge but also as organs for the ideological reproduction and legitimation of particular constructions of reality" (Gray, 2010, p. 714). From a socio-economically informed point of view and in search of the representational repertoires of the world of work in the ELT coursebooks, Gray (2010) investigates the most widely used books and sorts out the proportion of work related content and the extent to which this content is represented by neo-capitalist values such as branding an outstanding commodified discursive self. Grounded on a multi-semiotic analysis, the study also focuses on the visual representations and lists the celebrities whose life stories and identities are situated in the coursebooks and branded/submitted to the notice of language learners. The results reached through an in-depth analysis of the text books reveal that "choice, individuals and cases of spectacular success dominated the content which is interpreted as mediating the reproduction of neo-liberally legitimate subjectivities through coursebooks" (Gray, 2010, p. 736).

In a recent survey undertaken by Masuhara, Hann, Yi, and Tomlinson (2008), EFL course books are evaluated in connection to their pedagogic values across criteria such as publishers' claims, flexibility, syllabus, pedagogic approach, topic content, voice, interactions, teachability and even through this pedagogically embedded perspective, the results are found to be indicating that in most of the course books if not all "a particular western native variety is taken as a model but it is disguised under names such as natural spoken English in context, natural conversations and relevant and authentic English" (Masuhara, Hann, Yi, \& Tomlinson, 2008, p. 297). According to them, the aim of this is to take learners to the prescribed norms of pronunciation, vocabulary, grammar, and expressions. The absence of realistic content and avoidance of controversial topics are also mentioned among the shortcomings of many coursebooks.

A similar concern regarding the exclusion of certain life styles from course books is also voiced by Nohl (2009), who researches the opportunities for intercultural education in textbooks and mentions the cruciality of representing social actors with their multiple identities instead of a single and unchangeable trait they possess (Nohl, 2009, p. 65). Building on a variety of examples from Turkish and German coursebooks, he discusses how certain tasks that picture certain social actors associated with their single personal traits as in a matching activity featuring sentences like "this person is a Muslim" and "This person has a German passport" may undermine the chances for a multi-dimensional collective social practice. For him, text books may either serve the reproduction of stereotyped representations or promote intercultural education. 
Various studies, therefore, have dealt with issues of identity and how identities are represented along the pages of the ELT coursebooks, each with a distinct focus on particular aspects of the relations formed between the addressees of the coursebooks (or viewers of the images) and the coursebook content. All these discussions, in effect, are centered around the "semiotic power" that circulates multi-modally throughout the semantic repertoires of the coursebooks. However, in order to reach a clearer view of what is going on in the "image" part of this semiotic landscape, photo ethnographically informed semantic analyses need to be employed.

\section{Scope for Photo Ethnographic Research on the Peopled Images of the ELT Coursebooks}

As a meaning making practice, "photography" marks a discursive space in the ELT coursebooks whereby an interaction between the visually represented social actors and their viewers is established either at a conscious or subconscious level. At the one end of this interaction lies the locally situated global English learner ready to indulge himself/herself into the English speaking world (as is usually denoted by a high level of willingness to communicate with and integration into the global English speaker community WTC) while at the other end is a number of social actors depicted from a certain angle and distance with a certain subjective stance towards the individuals or groups. In this sense, peopled photographs of the ELT coursebooks may also serve a manipulative function in guiding and shaping the perceptions of their viewers through the endless interdependency formed between perception and meaning (McDougall et al., 2006, p. 2). In order to interpret the relations between the photographed social actors and their viewers, a variety of approaches dealing with distinct characteristics of the visuals are highlighted in the literature. In a recent study, Baetens (2013, p. 180) names 3 distinct macro frames of analysis each with particular foci on certain aspects of the image such as its material properties, uses and cultural value/social status.

A more specific and systematic way to interpret the semantic relations formed between the visually represented social actors and their viewers is offered by Kress and Van Leeuwen (1996, p. 148) in their guide to "reading images". Grounded in a socio-semiotic theory of representation, their systematic-functional account of "visual grammar", offers tools for interpreting the interactive meaning relations formed between the viewer and the depicted social actors through certain "visual signals" inherent in the image. As opposed to what the wording "grammar" may imply, this approach is not intended to undertake a rigid structural investigation restricted to a monolithic point of view, but rather seeks for multiple ways to analyze "the meanings of regularities in the way image elements are used" (Kress \& Van Leeuwen, 1996, p. 1). Each of these visual signals, minimally relating to the distance (framing size), angle (perspective) and the gaze of picturing, mark the realization of an "image act", as is highlighted in Table 1.

Table 1

Realizations of Interactive Meaning Relations Formed Between the Represented Social Actors and the Photographer/Viewer

\begin{tabular}{|l|l|}
\hline Visual signal & Image Act Realized \\
\hline Gaze at the viewer & Demand \\
Absence of gaze at the viewer & Offer \\
Close shot & Intimate/ personal \\
Medium shot & Social \\
Long shot & Impersonal \\
Frontal angle & Involvement \\
Oblique angle & Detachment \\
Higher angle & Viewer power \\
Eye level angle & Equality \\
Low angle & Represented participant power \\
\hline
\end{tabular}


In this network of relationships, a gaze at the viewer by the social actor(s) is interpreted as an attempt to establish direct contact with the imagined viewers of the photo, by creating a mental "you" in the place of the addressee. The represented social actor, therefore, is the subject of his/her own message, actively appealing to the imagined viewers and "demanding" his/her intended kind of relationship from them, be this either one of a hate or affinity in varying degrees. On the other hand, the absence of gaze at the viewer points to a lack of direct contact with the viewer, and is interpreted as an indicator of "detachment" from the depicted social actor(s). In this case, a mental barrier between the represented social actors and the imagined viewers is erected. The viewer and the represented are "disengaged"; the represented social actor is viewed unaware of being photographed and made the object of the information "offered" by the producer of the image functioning as an "object of contemplation" for the viewer.

The close shot, medium shot, and long shot distinction relates to different sizes of framing, each of which comes to signify varying levels of intimacy formed between the imagined viewers of the photo and the represented social actors. When the social actor is photographed from close-up (showing the head and shoulders of the subject till the waist - within a distance of touch), the kind of social relation formed is that of an "intimate" one whereby the subjects are personally recognized. The medium shot photo (showing the full figure of the social actors) is a marker of "social" distance that goes beyond the borders of "personal" relation and takes a more "formal" character. In contrast, a long shot photo (the figure occupying half the frame and less) is a sign of "public" distance whereby the social actors are represented a position of "stranger" to the viewers. In this kind of loose proximity relationship, the social actors remain as "objectified" and "impersonal" others without individual recognition of their feelings, mimes, and gestures to the viewer community.

The perspective of the photo - the angle the photo is taken from-forms a further point of consideration for the "attitude" or "viewpoint" adopted by the producers of the photo towards the represented social actors in a variety of ways. The divide between the frontal angle (the camera facing the social actors) and oblique angle (the camera viewing the social actors from sidelines) shots implies either the viewers are fully involved with the social actors or not. While, the social actors depicted from a frontal angle are positioned as participants of "our world", those depicted from an oblique angle do not; they are viewed in their own worlds, sharing a practice of "their own" outside the domain of the mentally drawn world of "ours". In addition to this distinction going on at the horizontal level of perspective, another distinction between the various degrees of vertical angle is also employed by visual ethnography to interpret the power relations formed between the represented social actors and the viewers. When the social actors are viewed from a higher angle so that the represented social actors are below the eye level of the viewers, the viewers are located to a position superior to the represented social actors. Those in the photo are aligned inferior roles and are made prone to an exercise of symbolic power. The low angle shot of the social actors, on the other hand, points to another asymmetrical power relationship whereby the represented social actors gain superiority over the viewers. Examples to this kind of power realization in visual language include elevated representations of various institutional identities such as a judge in the court, a police officer, a teacher or a prisoner guard photographed on horseback (Kress \& Van Leeuwen, 1996, p. 140). It is the viewer then, who is subject to an exercise of symbolic power. On the other hand, the eye level shot photo enables a relationship of equality between the represented social actors and the viewers of the photo treating them as equals of the continuum.

Apart from these systematic tools (the gaze, framing size and perspective) widely employed for researching visuals, other tools offered by Critical Discourse Analysis for conducting textual analysis can also 
form a common ground for understanding the multi-faceted relationships established between the represented social actors and the viewers of these representations. In this sense, the socio-semantic inventory, particularly the categories of exclusion, role allocation, genericization/specification, assimilation/individualization and categorization are crucial for a thorough interpretation of the visual representations (Van Leeuwen, 2008). A consideration of these categories may give out the following questions corresponding to each area of investigation:

- Exclusion-Are there any specific groups of people or individuals not represented in the visuals while they are normally expected to be present?

- Roles (role allocation) - Are specific groups of people or individuals depicted as the agents of actions that are downgraded, trivialized, criminal, evil, etc.?

- Specific - Generic (assimilation) - Is there any group of people shown as ahomogenous group (is there a denial of their individual characteristics by reference to their similarity)?

- Individuals and groups-Are the social actors depicted individually or in groups by diminishing their individual differences?

- Categorization-Are the social actors depicted with reference to their cultural characteristics/standard attributes (negative cultural connotations) or their biological characteristics/standardized exaggerations of physical features (negative racial stereotyping)?

The above discussed variety of ways suggested for interpreting visuals only mark a tradition in the whole literature of photo - ethnographic research dedicated to pinpoint the "ideologically colored angles" of the visual language (Van Leeuwen, 2008, p. 136). The graphical emphases on certain features of an image, its colors, saturation, mode (i.e., sepia, black \& white), layout can each come to impact the viewers' stance towards the portrayed people to an extent, yet the variety of ways to view an image is only restricted to the number of perspectives its viewers hold (Van Dijk, 1998, p. 201). A research design inspired by photo ethnographic point of view, is therefore, necessary to highlight the ELT coursebooks' repertoire of visually represented social actors with a particular focus on how certain identities are portrayed.

\section{Methodology}

The peopled images $(N=649)$ of the 7 most widely traded intermediate level ELT coursebooks in Turkey ${ }^{1}$ were put under focus in order to portray how the social actors belonging to various national, ethnic, religious and gender identities are represented and what kind of relations are formed between the represented social actors and the assumed viewers of these images. The 7 coursebooks that were determined following a brief market research with the publishers include Face2Face $(n=73)$ and English Unlimited $(n=84)$ by Cambridge, New English File $(n=100)$ and English Result $(n=102)$ by Oxford, Speakout $(n=83)$ by Pearson, Global $(n=$ 97) by Macmillan and Upstream $(n=110)$ by Express Publishing. In order to reach systematically refined data in line with the aims of the study, the social actor interaction network offered by Van Leeuwen (2008, p. 141) has been employed as the primary tool of investigation for analyzing the related visual content.

Figure 2 is based on the - earlier discussed - interactive meaning relations network developed by Kress and Van Leeuwen (1996) and includes identical image act realizations. Thus it gives a chance to classify the images systematically depending on their objective qualities of framing size, perspective and gaze facilitating

\footnotetext{
${ }^{1}$ Depending on the data obtained through a local market research on various publishers in Istanbul.
} 
both quantitatively and qualitatively grounded interpretations.

The interpretations of the quantitative results reached at the end of the visual analysis re-voice the previously touched issues of otherization, disempowerment, exclusion and homogenization over the representational repertoires of the ELT coursebooks and indicate to a disproportionate distribution of certain representations as well as occurrences of symbolic power exercise towards the representations of social actors from "outer circle" or "non-English speaking" world.

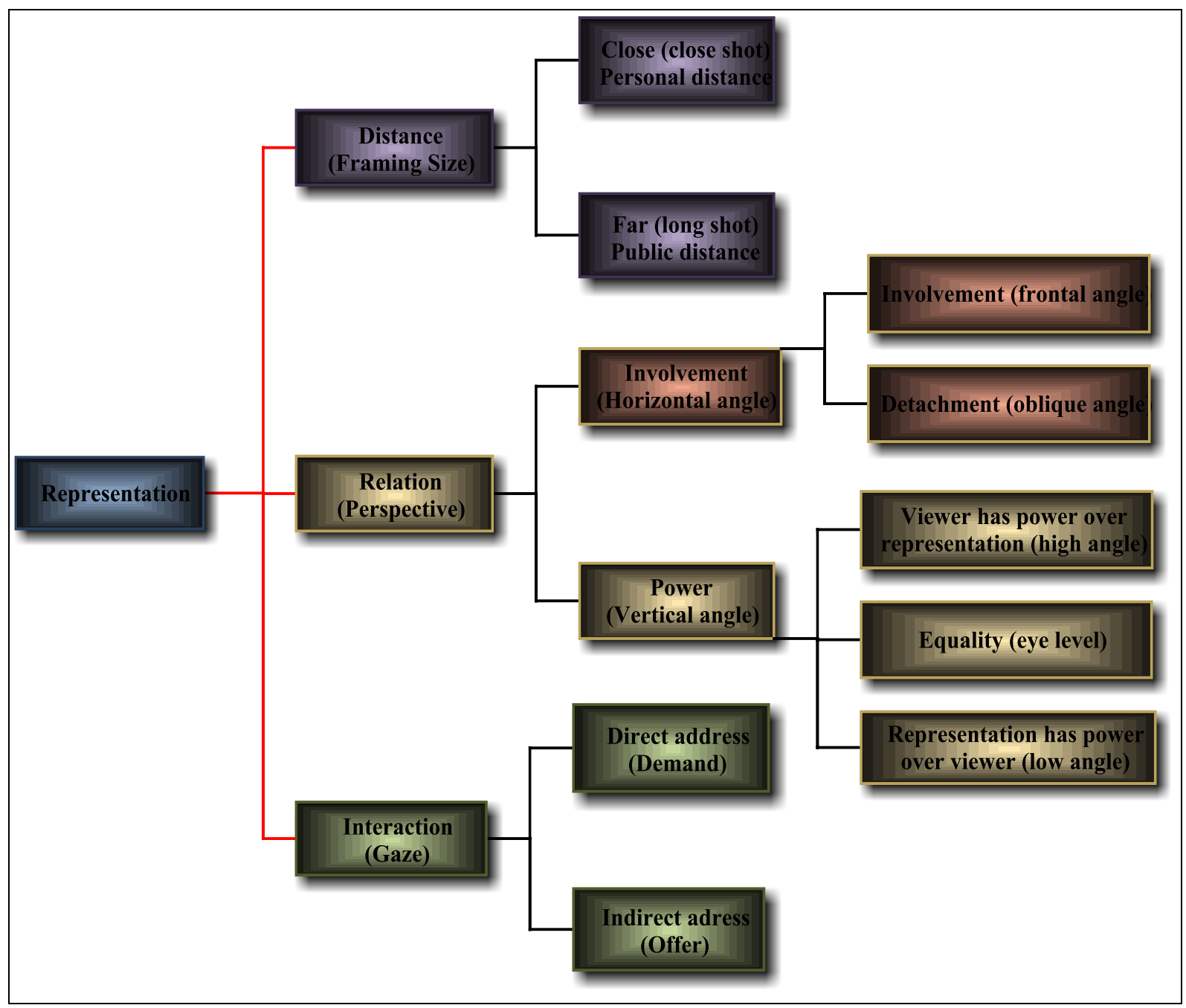

Figure 2. Image act realizations and interactive meaning relations formed between the represented social actors and the viewers adopted from Van Leeuwen (2008, p. 141).

\section{Framing Size Matters: Keeping the Distance With the "Other"}

A majority of texts in the coursebooks are either constructed around or construct themselves-a "norm group" that may come to imply a "mental we" as the reference group, thereby defining a subjectivity through which the reader is invited to view the world. Therefore, seeking response to the question of "through whose eyes do we view people?" is of prominence for revealing several discursive practices of stereotyping, exclusion, disempowerment, assimilation and alike towards social actors identified with certain ethnic/gender/cultural identities. Multi-modal means of expression work throughout these texts to define "us" and "the others". Hence, 
the "other" does not necessarily have to be drawn textually; it can be implied through extra linguistic channels such as proximity and gaze. The visual depiction of a subject from a particular distance may as well be an indicator of the social distance formed between the viewer and the depicted social actor. In this equation, the long shot picture of a social actor and a close shot picture of him/her tell the viewer about the positioning of the subject either as someone among us or as someone outside the borders of the "mental we" the photographer undertakes for the viewers. In order to highlight how this distancing mechanism works throughout the ELT coursebooks, two contrastive depictions of social actors from the coursebooks under investigation are provided (see Figure 3).

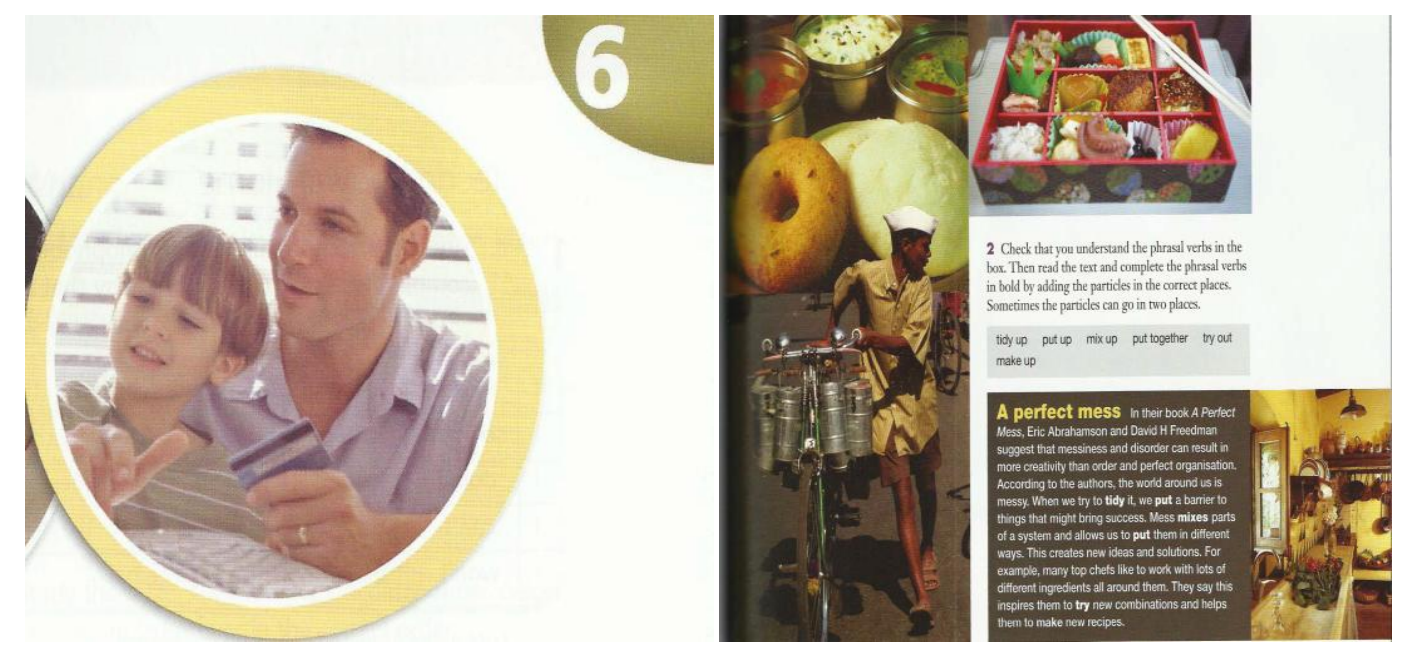

Figure 3. Social actors depicted within personal v.s. public distance from Upstream and Global.

In the depiction taken from Upstream Intermediate (left) the social actors associated with consumer society norms (father and his son holding a credit card in front of the computer screen) are framed so that they occupy nearly the whole frame with a zoom on the upper part of their bodies until their shoulders. Regarding the size of framing, they are portrayed within the borders of "personal distance" as social actors among "us". The depiction from Global Intermediate (right), on the other hand, depicts an ethnically identified social actor also associated with low-wage worker identity (a delivery boy) from a long shot distance aligning the whole body of the social actor within the frame. The delivery boy is, therefore, located further to "us"-the imagined viewer community presumed by the photographer-indicating a non-personal, public relationship established between the social actor and the viewers. In comparison to the modern image of the social actors associated with a predominantly western norm behavior in the first depiction, the visual clues about the social actor captured in the second depiction emphasize the existence of another "extraterritorial" world, in reasonably public distance to us. The absence of the African social actor's gaze at the photographer also locates him as the object of the message offered by the photographer rather than as a social actor actively demanding his own message and kind of relationship from the viewers.

Similar practices of distancing are not quantitatively vey remarkable as all the 7 coursebooks investigated feature more close-up depictions of social actors than long shot depictions by number. Overall, only 73 of the 649 peopled photos in the coursebooks contain long-shot depictions of social actors (irrespective of their gender or ethnic identities), forming approximately $11 \%$ of all the peopled images. On the other hand, in terms of close-up depictions, 442 out of 576 representations (77\%) belong to social actors from the English speaking 
world, leaving the other $23 \%$ for the close enough portrayal of the international social actors identified with the non-English speaking world, which may well come to mark the domination of a pro-anglo centric perspective. In this sense, although in figures distancing and otherization do not come out as significantly recurring practices, the vast number of close shot portrayals belonging to the English speaking world may indicate to an asymmetrical relationship drawing a thin line between "us" and the "other". Moreover, singular occurrences of distancing encountered along the pages of the ELT coursebooks, even in those that are in the claim of including a multitude of multi-cultural variety, deserve to be spotted when they are directed towards social actors associated with a particular identity. The depictions of social actors below, taken from Speakout Intermediate coursebook are intended to highlight how such singular occurrences of distancing may exclude ethnically or culturally defined identities from the visual experience domains of the viewers as well as how social actors can be utilized for decorative purposes.

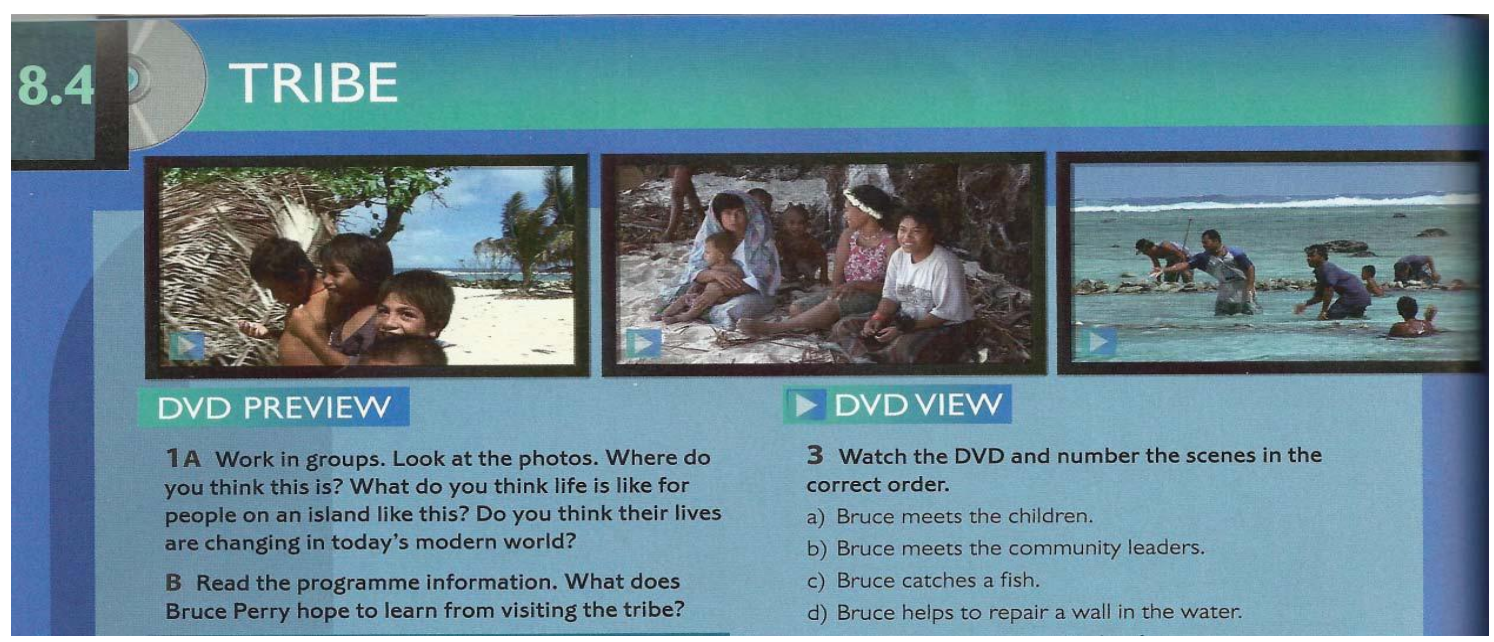

Figure 4. Social actors depicted as the decorative units of a "remote exotic land" from Speakout.

Represented under the heading "tribe" (see Figure 4), these photos captured from a video about the lives of people living on an island, encapsulate children, women and men in separate frames reflecting the strictly categorized labor division attributed to the community by the producer of the images. The children, women and men are pictured separately undertaking distinct activities in the work order of the community. Only in the first frame are the viewers invited to view the social actors from a close-up, as indicated by the relatively bigger size of framing employed (upper part of the social actors occupying approximately half the frame). The second and the third depictions, however, put a public distance between the represented social actors and the viewers, decreasing the extent of their involvement into "our" lives - the lives of the imagined viewer community. The representations of the social actors, therefore, stand for representing a reality far from the viewers' worlds of experience. They suggest a "primitive" way of life compared to the assumed viewers' "modern" lens shared by the photographer. This graphic interpretation is also supported by the accompanying activity instruction that reads "Do you think their lives are changing in today's modern world?". The so denoted "their" in this instruction, bears hardly any difference from Caliban's role in Shakespeare's famous play The Tempest, representing an uncivilized world far from the reach of its "modern" counterpart. The people under focus are viewed within the strictly western sourced nominations of "tribal" as opposed to the modern belongingness of the so-positioned civilized viewers of the image. 
Following the discursive evolution of relevant terminology on being barbarian, savage, and primitive, it is clear that once the word "civilization" is uttered, savage naturally becomes its antithesis (Kuper, 2005, p. 30) as it is experienced both visually and verbally in the pages of this particular intermediate level ELT coursebook.

\section{Tracking The Gaze: An Eye on "The Objects of Contemplation"}

Gaze, in terms of the current photo - analytical study, is an indicator of the type of interaction formed between the depicted social actors and the viewers. When a social actor is photographed looking at the focus, she/he is considered to be actively sending his/her own intended message to the viewers because she/he is addressing the viewers directly, constructing the message of her desire by using the preferred facial expressions, gestures, mimes and more to tell about her "self". In other words, it becomes her/his own choice to appear before an audience this way and not that way. At the opposing end of the continuum lies the absence of a direct gaze at the focus, more precisely an uninformed shot, which gives way to the practice of "passivation" on the part of the social actors pictured. The social actor, then, takes on the role of a "décor" employed by the photographer to convey the message constructed by himself/herself in an attempt to explain the social actor's world without consulting to the actual message they might be carrying through their looks, feelings, and mimes. With regard to "gaze", the statistics in all the 7 coursebooks point out to an excessive number of uninformed shots, although the gap between uninformed and fully addressing shots seem insignificant. Statistically speaking, 400 of the 649 peopled images in all the coursebooks feature social actors who are unaware of being photographed, amounting to a rate of $64.4 \%$. Of these uninformed shots 315 belong to social actors from the English speaking world while the remaining 85 represent international social actors mostly from non-English speaking world (traditionally termed as outer and expanding circles). The practice of visual passivation, therefore, is more common an act for English speaking social actors than for international social actors, at least statistically. As for the female/male divide, $55.59 \%$ of male social actors and $51.65 \%$ of female social actors in the books are pictured uninformed without a gaze at the focus.

Although statistically insignificant, singular occurrences of passivation signaled by an absence of gaze might imply asymmetrical positioning with regard to the type of interaction formed between depicted social actors and the viewers. The two photos below (see Figure 5), taken from New English File and English Result, represent how the tension between the presence and absence of gaze at the focus might account for the dispatch drawn graphically between "us" and "them".

The picture on the left depicts two social actors portrayed with their own demanded message. Their looks deliberately directed at the camera and their glimpse tell the viewers of "happiness" as displayed by the social actors. In other words, they demand the type of relation to be formed between themselves and the viewers of the photo, address the message of happiness through a presentation of the self. On the other hand, in the second photo, the social actor is not the subject of her own intended message; instead she is put there to express not her feelings but the feelings attributed to her from an external perspective - that of the photographer. In this equation she is there to realize whatever message is offered by the photographer and not allowed to undertake her own intended meaning, nor demand her preferred way of interaction with the viewer. The viewer is not allowed to interpret how the social actor is feeling in reality, but instead invited to believe (looking at the facial clues such as pouting) in her implied feeling of discontent pre-packed by the photographer. As indicated by several other cases of uninformed shots that circulate in the pages of the coursebooks, gaze plays a critical role 
in determining the position of the social actors with regard to the viewers. They can come out either as active interactants articulating a visual "you" or as passivated objects of "voyeur" who are being watched through a cam (Van Leeuwen, 2008, p. 142).
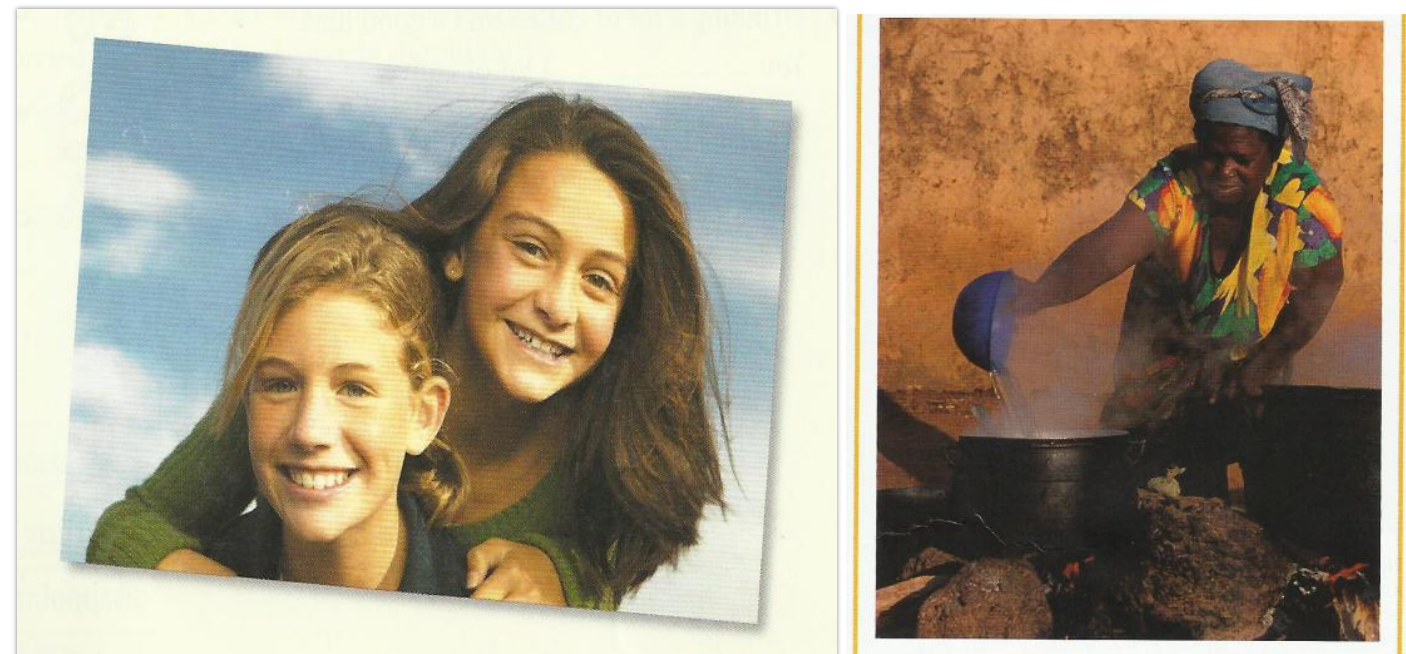

Figure 5. Social actors directly addressing the viewer from New English File (happiness) v.s. Social actor object of indirect address from English Result (implied discontent).

\section{Perspective and Power Relations: The Implied Disempowerment of the "Other"}

Both the vertical and the horizontal angles from which the social actors are pictured tell us about the power-play in effect throughout the visual landscape of the coursebooks. In terms of vertical angle, the viewers of the images are positioned around an array of possible loci as superiors, inferiors or equals in relation to the social actors portrayed in the visuals. In this form of power relationship the more balanced view foresees an eye level relationship between the interactans whereby the social actors and the viewers share the power. At the two extremes, however, either the viewer or the viewed social actor has power over the other; and this inevitably brings about the act of "disempowerment" for one of the parties. When disempowerment is targeted towards social actors who are exposed to stereotypical and trivializing treatment in real life, or a group of social actors that are categorized as culturally "different", the vertical angle of photography gains increased prominence.

In terms of vertical perspective, ELT Courseboooks seem to be representing an unfavorable power distribution among the social actors that belong to the English Speaking world and that do not. As indicated by Figure 6, in 5 of the 7 coursebooks the rate of international social actors who are disempowered by a higher angle shot outweigh the rate of disempowered social actors identified with the English Speaking World. Outstanding are the percentages of higher angle shot international social actors amounting to $33 \%$ in Speakout, 25\% in Upstream and 18\% in New English File. In turn, these figures can well be interpreted as an implied practice of "otherization" as the English speaking world is far less disempowered.

Turning the focus the other way round, the question reads as "who is empowered?" and the answer to this question has the potent to verify the existence of an anglo-centric perspective at play. However, a close investigation into the peopled images reveal that out of 649 peopled images in the 7 coursebooks only 15 feature social actors depicted from a lower angle, a vast majority, rightfully including eye-level shots. 
On the other hand, exceptional and singular practices of disempowerment pointed towards various identities represented visually along the pages of the coursebooks can be suggestive of a biased-perspective to the same extent. In this sense, the following peopled images that are both focused on the topic of school life and that feature social actors obviously belonging to divergent cultural contexts form a significant example of how disempowerment can influence the viewers' perspective towards the visually implied "other".

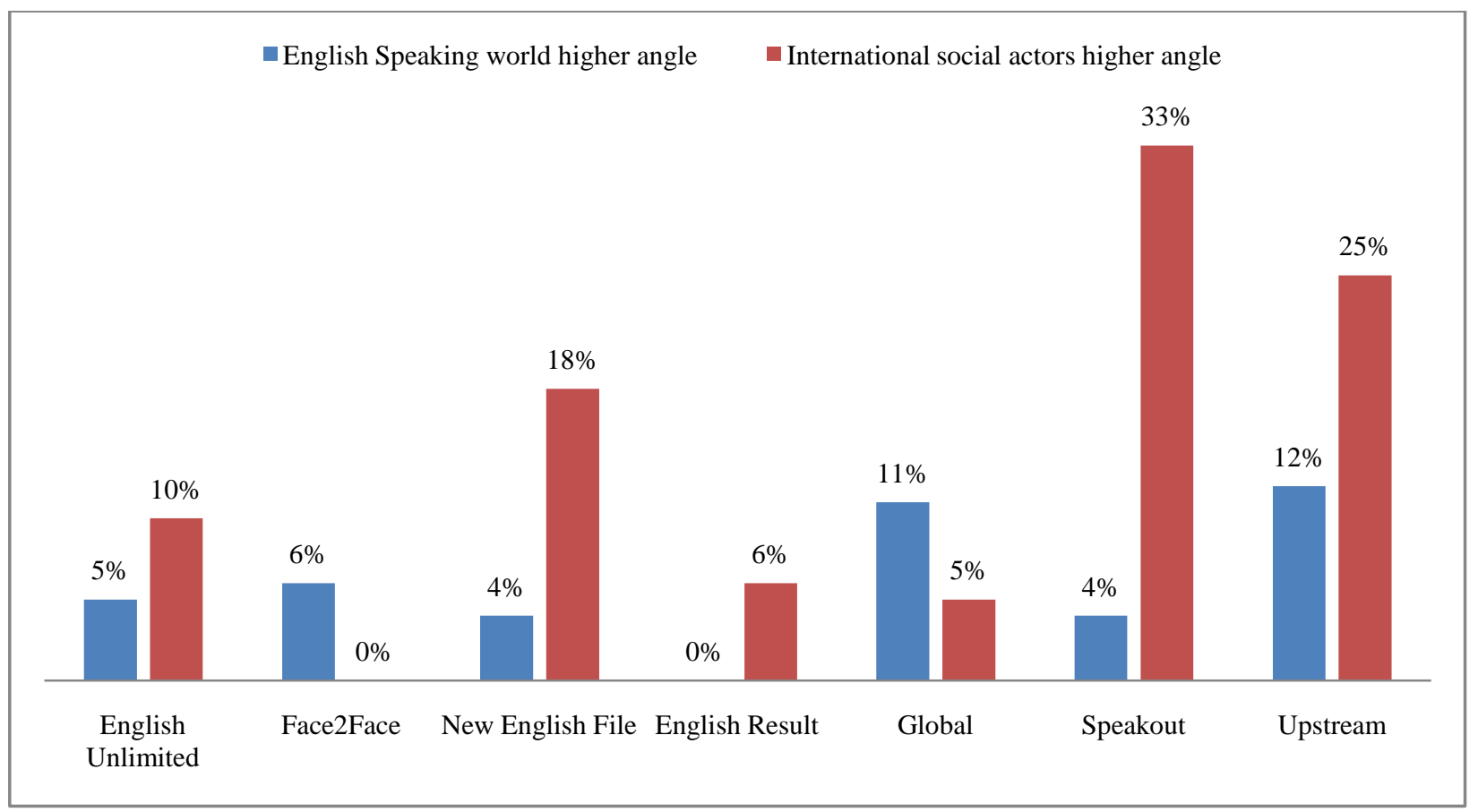

Figure 6. Rate of social actors photographed from higher angle (social actors disempowered).
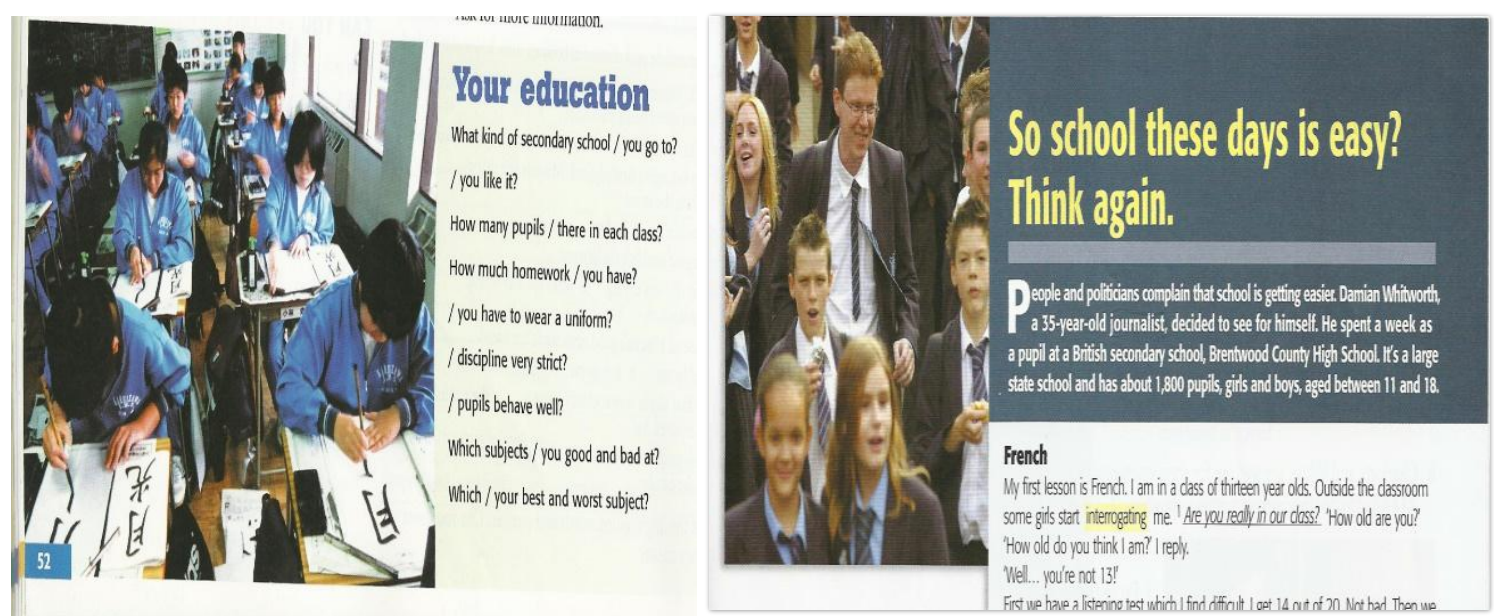

Figure 7. Culturally categorized social actors portrayed from higher v.s. eye-level angles from New English File.

The first of the images taken from New English File portrays social actors writing Japanese letters in their notebooks, all escaping their eyes from the focus and pictured from a higher angle. The higher angle of shot obviously positions the viewers to a role superior to that of the social actors depicted. Moreover, they are passivated by an absence of gaze and found not transmitting their intended messages to the viewers; they are 
there to convey an external message of school life undertaken by the photographer. This message is homoglossic, focusing on sameness and uniformity as implied by the graphical emphasis on the exact same color of the uniforms, precisely lined rows and all students looking in the same direction, dealing with the same thing. In other words, no individual student in the picture is given the right to release his/her own message besides being the trivialized décor of the photographer. In contrast, the second picture found on the same topic of the same coursebook features social actors from a British Secondary School with an eye level angle, and with their faces individually recognizable. The focus of the second shot is not on uniformity; rather it is on individual difference as no two people are pictured looking the same direction or doing the same thing; even their hair styles reveal a freedom of choice allocated to the social actors.

Although less remarkable than the power relations characterized by the vertical angle of the photo, the horizontal angle is also a common marker of power exercise practiced in the visual domain. The photo of a social actor directly facing the camera and that pictured from an oblique angle imply two opposing kinds of relationship established between the social actors and the viewers, first being attachment and the second being detachment. Various practices of oblique angle shots indicating detachment or non-participation into the viewers' worlds can be found to be spotting social actors from Non-English Speaking contexts. Upstream, Face2Face, and Speakout take the lead in picturing the international social actors in detachment (in peripheral roles) with oblique angle shooting rates of $100 \%, 50 \%$, and $47 \%$ respectively.

\section{Variety Lost: Assimilation, Categorization, Homogenization}

Inept to be expressed via numbers, emergent and equally impactful practices of exclusion, assimilation, categorization and homogenization also spread around the visual sphere of the coursebooks and populate the minds of the viewers in potentially stereotypical ways. Among these visual practices, the homogenized depiction of social actors who are categorized as "culturally different" in assimilative ways take the front. Particularly in the photos of social actors portrayed as groups, it is quite common to come across a focus on their common cultural characteristics by diminishing their individual differences. In this kind of photography, the image conveys a single, homoglossic message about the group of individuals as if they are supposed to do the same things, dress the same way or have the same physical attributes in real life. However, this message can be easily falsifiable in actuality as no two individuals follow the same story lines. The three pictures in Figure 7 taken from Global are put there to exemplify how coursebooks can sometimes be (either intentionally or unintentionally) employing such visually reductionist and stereotypical tools. In the first and second pictures the social actors are categorized in relation to their beliefs, with an emphasis on the similarity of their clothes, haircut and even their color of skin - a biological attribute. They are pictured as one and uniform; as a homogenous group of people with few-if any individual differences. The viewer, therefore, is not given the opportunity to meet an individual in personbut forced to view the whole community as members of the same practice in a rather reductionist manner.

In the third depiction (see Figure 8), which is also taken from Global, in the midst of a blurred group of "white collars" stands a man whose face, mimes, and gestures are visible although he is uninformed of being pictured. While the man's face is clear, the faces of the surrounding community are blurred on purpose, most probably to add an aesthetic effect to photography. Although this social actor is recognized individually, he is still depicted with a focus on sameness, as any member of a community all wearing white, all in a rush, and all dealing with some papers; undertaking a generalizing summary of modern work life. 

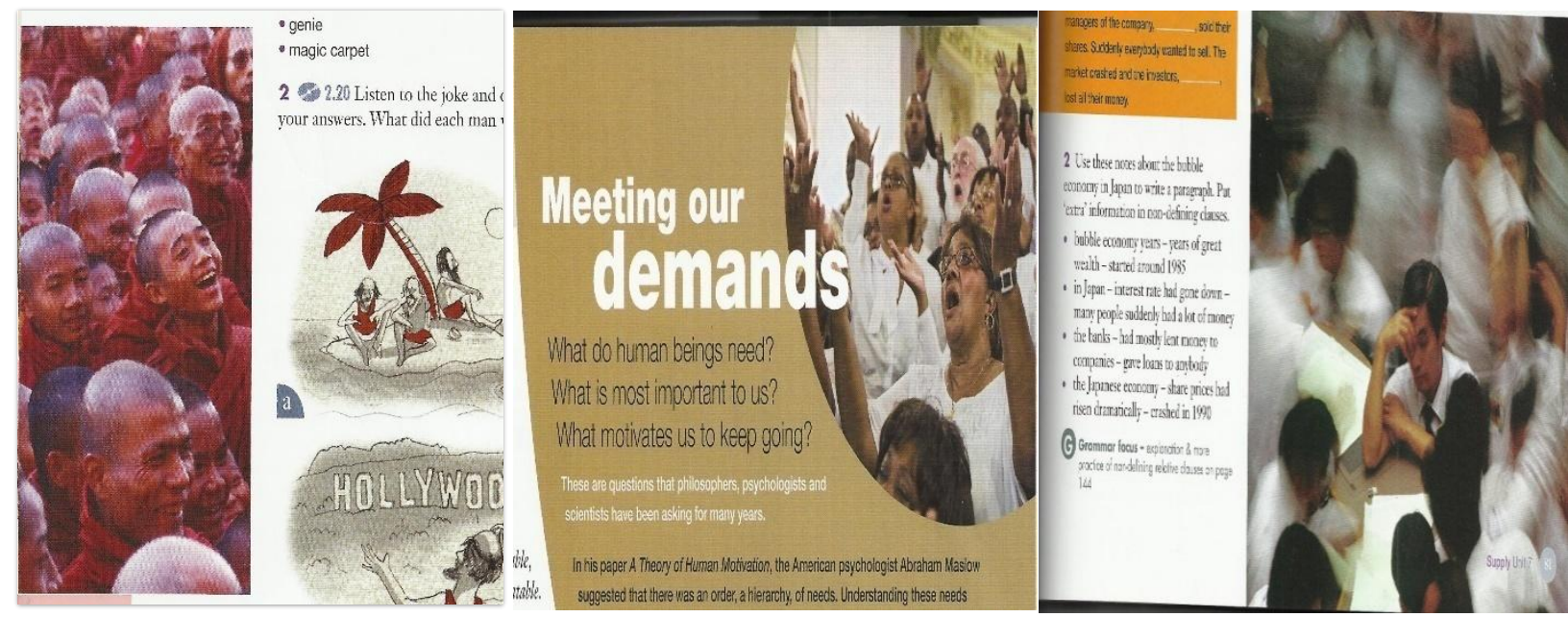

Figure 8. Social actors subject to cultural categorization and assimilation from Global.

\section{Discussion}

In this photo analytical study, the social actors who are depicted in the visuals of the 7 intermedate level ELT coursebooks were investigated with regard to the relationship they establish with the viewer. The areas of investigation included relations of distance (whether the social actors are pictured from long distance or short distance), relations of involvement (whether the social actors are pictured from oblique angle or frontal angle) relations of power (whether the social actors are pictured from higher angle, equal angle, or lower angle).

The results of the analysis indicated that inner circle (English Speaking World) social actors and international social actors were not pictured in equal proportions in the coursebooks. In all the 7 coursebooks, the number of visual depictions for inner circle social actors were more than those for the international (outer and expanding circle) social actors. Particularly in the coursebooks Face2Face, New English File, English Result, Speakout and Upstream the number of visual depictions for international social actors remained significantly low in comparison to the visual depictions of the inner circle social actors. In terms of male-female social actor distribution in the pictures, the coursebooks represented a more balanced view with a few exceptions (Global, Speakout, and Upstream) in which the number of depictions of male social actors exceeded the number of female social actors.

Apart from the significance of numbers, outstanding are the ways inner circle and international social actors were depicted throughout the coursebooks. Looking at the results reached in the analysis part, the following statements on the visual depictions of the social actors can be made:

- Social actors representing the Non-English Speaking World (traditionally termed as outer and expanding circle countries) are depicted from a remarkably longer distance than the social actors representing the inner circle countries in the coursebooks Face2Face and Speakout.

- International social actors are pictured from oblique angle more than the inner circle social actors in 5 of the coursebooks. In terms of involvement this indicates to a detachment from the action pictured and a trivialized role allocation when compared to that of the actor.

- In 5 of the coursebooks more higher angle shots are employed for depicting international social actors than for inner circle social actors, which is clearly suggestive of an asymmetrical power relationship, and an elevated anglo-centric perspective. 
- In terms of interaction the number of pictures where social actors are pictured without gaze (not looking at the focus) seems balanced. However, in New English File and Upstream the number of uninformed shots is higher for the outer and expanding circle social actors, signifying a lack of interaction between the viewer and the depicted. In cases of no interaction social actors are made the object of the intended meaning and not the active agents of their own intended meaning.

- In a great number of cases, social actors from outer and expanding circle countries were pictured as a community rather than by an individual shot. In these cases, which are sampled in the related part of the analysis, social actors are assimilated through a focus on the similar features of the group of social actors. Throughout the analysis this kind of categorization was found to be based on biologic properties of the social actors as well as their shared cultural practice, making them prone to stereotyping by the learners.

These results point to the critical and so far underestimated role of visuals in establishing relations between the worlds of the learners and the social actors depicted. Visuals are found to construct subject positions for the learners who view the images, and influence the way they view a variety of people from different backgrounds. It was revealed as a result of this analysis that the subject positions constructed for the learners to take on - or rather the identities ascribed by the visuals of the coursebooks to them - has a rather downgraded image of the outer world.

\section{Conclusion}

Over the last century, the world has seen a revolutionary turn in the field of visual communication moving rapidly from the founding technologies of capturing a still image to the more sophisticated advancements at recording, playing and sharing frames of moving images. Throughout this historical shift the evolutionarily developed pace and capacity of the human brain in processing visual information has been the main trigger. As a result of such revolutionary steps in technology as well as our own cognitive revolution, the act of seeing has gained conceptual, cultural, ideological dimensions in addition to its most basic retinal meaning. Seeing, today, involves reading the ideologically colored angles embedded in the images, raising consciousness against the stereotypical representations and being fully aware of the powers at play in the semiotic landscape we are situated in.

The current study on the visual depictions of social actors represented in the ELT coursebooks offers just one possible way of seeing that picture. The view encoded by this study, however, is not a quite favorable one: in most of the coursebooks a thick line between "us" and "them" is graphically drawn through several practices of otherization. An elevated position of the "English speaking world" (inner circle countries) is clearly evidenced by the disempowerment of the social actors that do not belong to the "English speaking world". This disempowerment is mostly signaled by the use of the vertical perspective so that the social actors are viewed from a higher angle. In addition, a "personal" kind of relation between the social actors and the viewers is avoided by the use of increased framing size that picture the social actors as personally unrecognizable figures kept at a "public distance" to the viewer. Passivation of the social actors indicated by the absence of gaze; assimilation, categorization and homogenization realized by diminishing the individual differences between the social actors are all practices of graphical discrimination committed against the "other" who are portrayed along the pages of the coursebooks. Various images in the coursebooks still offer a single and uniform picture of "African culture", "Indian way of life" or "Chinese education system" and risk influencing the viewers (in this case the language learners) in stereotypical ways. 
As a result, in response to the question of "who populates the visual landscape of the ELT coursebooks", for most coursebooks"acolor-blind ideology" still forms a persistent answer. Although a multicultural discourse circulates among the claims of all the English Language Teaching coursebooks, an essentialist, conservative or soft form of multiculturalism acts as another disguise of the "anglo-centric" perspective as long as a truly pluralist multiculturalism informed by a trans-cultural approach is not put to work. In order to realize a pluralist multiculturalism, however, we need to see multi-modally; not only the linguistic and textual content of the instructional materials but also the visual, aural and spatial landscape they offer; we need to see not as voyeurs but as active and critical participants getting ready to transform this landscape from below.

\section{References}

Baetens, J. (2013). Image and visual culture after the pictorial turn: An outsider's note. Visual Studies, 28(2), 180-185.

Bedford, S. (2005). A critical perspective on the representation of racial identities in business english course books. Discourse Analysis: Theory into Research (p. 48).

Clare, A., \& Wilson, J. J. (2012). Speakout: Intermediate: Student's book with Activebook and My EnglishLab. Pearson Education Limited.

Collier, J., \& Collier, M. (1986). Visual anthropology: Photography as a research method. Albuquerque: UNM Press.

Dodey, D. (2010). Upstream. Upper-Intermediate: Student's Book/V. Evans, J. Doole. Express Publishing.

Gray, J. (2010). The construction of English: Culture, consumerism and promotion in the ELT Global Coursebook. Basingstoke: Palgrave Macmillan.

Hancock, M., \& McDonald, A. (2010). English result intermediate student's book. Oxford, England: Oxford University Press.

Kress, G. R., \& Van Leeuwen, T. (1996). Reading images: The grammar of visual design. New York: Psychology Press.

Kuper,A. (2005). The reinvention of primitive society: Transformations of a myth. Routledge.

Masuhara, H., Hann, N., Yi, Y., \& Tomlinson, B. (2008). Adult EFL courses. ELT Journal, 62(3), 294-312.

McDougall, S., Tyrer, V., \& Folkard, S. (2006). Searching for signs, symbols, and icons: Effects of time of day, visual complexity, and grouping. Journal of Experimental Psychology: Applied, 12(2), 118.

Nohl, A. M. (2009). Opportunities for intercultural education in textbooks. Education Science Society Journal, 7(28), 59-73.

Norton, B., \& Toohey, K. (2011). Identity, language learning, and social change. Language Teaching, 44(04), 412-446.

Oxendon, C. (2006). New English file intermediate student's book. Oxford: Oxford University Press.

Redston, C., Clementson, T., \& Cunningham, G. (2013). Face2face intermediate student's book. Cambridge: Cambridge University Press.

Shardakova, M., \& Pavlenko, A. (2004). Identity options in Russian textbooks. Journal of Language, Identity, and Education, $3(1), 25-46$.

Tilbury, A., Hendra, L. A., Rea, D., Clementson, T., Metcalf, R., Cavey, C., \& Greenwood, A. (2013). English Unlimited Intermediate Student's Book with DVD-ROMs (2). Cambridge: Cambridge University Press.

Van Dijk, T. A. (1998). Ideology: A multidisciplinary approach. London: Sage.

Van Leeuwen, T. (2008). Discourse and practice: New tools for critical discourse analysis. Oxford, England: Oxford University Press.

Watkins, F., \& Clandfield, L. (2010). Global: Intermediate Student's Book. Oxford: Macmillan. 